\title{
The Impact of Off-Patent Drug Acquisitions on Prices
}

\author{
Ravi Gupta, $M D^{7}$, Alexis Henkel, BA ${ }^{2}$, Howard P. Forman, MD, MBA $3,4,5$, and \\ Joseph S. Ross, MD, MHS $5,6,7$
}

\begin{abstract}
'Department of Medicine, Johns Hopkins Hospital and Johns Hopkins School of Medicine, Baltimore, MD, USA; ${ }^{2}$ Yale University, New Haven, CT, USA; ${ }^{3}$ Department of Radiology and Biomedical Imaging, Yale School of Medicine, New Haven, CT, USA; ${ }^{4}$ Yale University School of Management, New Haven, CT, USA; ${ }^{5}$ Department of Health Policy and Management, Yale University School of Public Health, New Haven, CT, USA; ${ }^{6}$ Section of General Internal Medicine, Department of Medicine, Yale University School of Medicine, New Haven, CT, USA; ${ }^{7}$ Center for Outcomes Research and

Evaluation, Yale-New Haven Hospital, New Haven, CT, USA.
\end{abstract}

KEY WORDS: Generics; Prescription drugs; Pricing; Acquisitions; FDA.

J Gen Intern Med 33(7):1007-9

DOI: $10.1007 /$ s11606-018-4372-3

(c) Society of General Internal Medicine 2018

$\mathrm{F}$ rom 2010 to 2015 , more than 300 off-patent drugs sold in the USA experienced price increases of $100 \%$ or more, ${ }^{1}$ including, for example, Turing Pharmaceutical's 5500\% increase in the price of pyrimethamine. Insufficient competition may be partly to blame, ${ }^{2}$ as pharmaceutical companies can acquire these drugs and dramatically raise their prices, even though patent protections or other market exclusivities have expired. ${ }^{3,4}$

\section{OBJECTIVE}

The aim of this study is to examine prices of off-patent drugs originally approved by the Food and Drug Administration (FDA), which exist in monopolies or duopolies, ${ }^{5}$ and were acquired by a new company after 2000 .

\section{METHODS}

We identified all brand-name drugs in tablet or capsule formulation approved by FDA since 1939. We focused on drugs in tablet or capsule formulation since inhaled drugs and many injectable drugs often use medical device technology subject to its own market exclusivity considerations, whereas infused drugs are predominantly purchased by hospitals and physician facilities. We excluded over-the-counter drugs, biologic therapies, nonmarketed drugs, reformulated drugs, and drugs with current patent protections or other market exclusivities. We then limited our sample to those brand-name drugs with 0 or 1 FDA-approved bioequivalent generic versions, as of April 2017. We specifically focused on monopolies and duopolies because the lack of

Published online April 23, 2018 competition makes products more susceptible to price increases. $^{2}$

For each brand-name drug, we determined whether its manufacturer had undergone a merger or acquisition or had transferred the drug license to another manufacturer (hereafter "drug acquisitions" or "acquired drugs"), using a Bloomberg Terminal, company press releases, Security and Exchange Commission filings, and news sources. Next, we collected all available wholesale acquisition costs for each brand-name drug and, if one was available, its generic version, using a Bloomberg Terminal. Depending on whether drug prices were available (Fig. 1), we used Wilcoxon matched-pairs signed-rank tests to compare prices before and after the most recent, post-2000 brand-name drug acquisition, as well as to compare the median brand-name and generic prices of both acquired and non-acquired drugs, using the most recent price available. Statistical analyses were performed using Stata 12.0 (StatCorp; College Station, TX) using a $p$ value of 0.05 .

\section{RESULTS}

Among 67 FDA-approved brand-name drugs with 0 or 1 currently marketed generics, 37 (55\%) were acquired at least once since 2000, whereas $30(45 \%)$ had not been acquired (Table 1). Among acquired brand-name drugs with pre- and post-acquisition prices $(n=37)$, the median post-acquisition price was significantly higher than the median pre-acquisition price (\$11.05 [interquartile range (IQR), \$3.99-\$25.82] vs. $\$ 4.69$ [IQR, $\$ 1.97-\$ 14.83$ ]; $p<0.001)$. Using the most recently available prices, the median price of acquired brand-name drugs $(n=37)$ was higher, though not statistically significant, than that of non-acquired drugs $(n=26)(\$ 22.12$ [IQR, $\$ 5.20-\$ 95.51]$ vs. $\$ 8.60$ [IQR, $\$ 3.14-\$ 41.27$ ]; $p=0.06$ ). Finally, of the 67 brand-name drugs, 23 (34\%) had 1 generic version. Using the most recently available prices, the median price of generic versions of acquired brand-name drugs $(n=$ 10) was higher, though not statistically significant, than the median price of generic versions of non-acquired brand-name drugs $(n=12)(\$ 9.26$ [IQR, $\$ 2.23-\$ 97.87]$ vs. $\$ 3.70$ [\$1.44-\$20.08]; $p=0.36)$. 


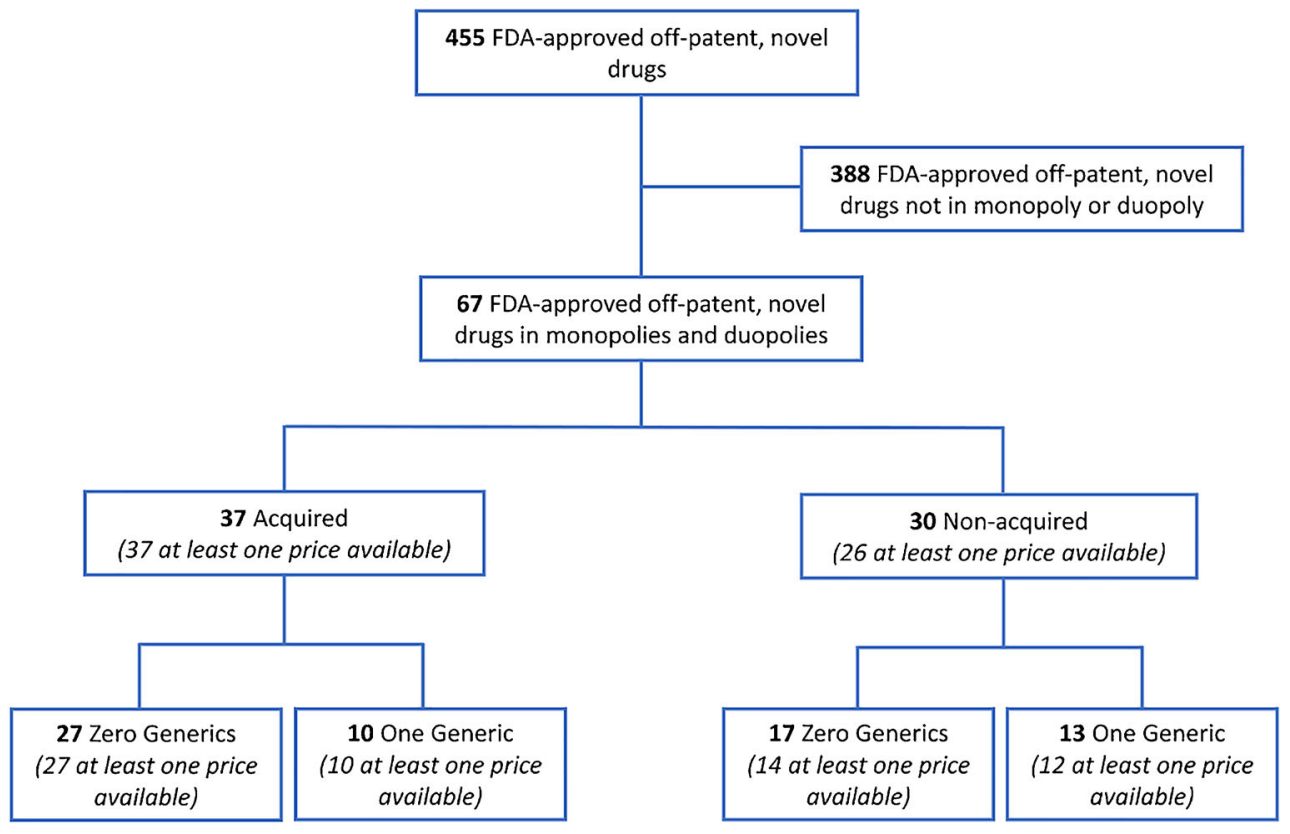

Fig. 1 Sample of FDA-approved off-patent drugs in monopolistic or duopolistic markets.

\section{DISCUSSION}

Among FDA-approved, off-patent brand-name drugs in tablet or capsule formulation and in monopolies or duopolies, more than half were acquired since 2000 , with their median price more than doubling after acquisition. These findings suggest that Turing's acquisition of pyrimethamine was not an isolated event and companies may be targeting these drugs for acquisitions and subsequent price increases. Acquired drugs were priced more expensively than non-acquired drugs, though the

Table 1 Characteristics of FDA-approved off-patent drugs in monopolistic or duopolistic markets

\begin{tabular}{|c|c|c|c|}
\hline Characteristic & $\begin{array}{l}\text { Total } \\
(n=67)\end{array}$ & $\begin{array}{l}0 \text { generics } \\
(n=44)\end{array}$ & $\begin{array}{l}1 \text { generic } \\
(n=23)\end{array}$ \\
\hline \multicolumn{4}{|l|}{ Acquisition status } \\
\hline $\begin{array}{l}\text { Acquired at least once } \\
\text { since } 2000\end{array}$ & $37(55)$ & $27(61)$ & $10(43)$ \\
\hline Not acquired since 2000 & $30(45)$ & $17(39)$ & $13(57)$ \\
\hline \multicolumn{4}{|l|}{ Approved for rare disease ${ }^{a}$} \\
\hline Orphan Designation & $15(22)$ & $12(27)$ & $3(13)$ \\
\hline No designation & $21(31)$ & $8(18)$ & $13(57)$ \\
\hline \multicolumn{4}{|l|}{ WHO essential medicine } \\
\hline Included & $18(27)$ & $14(32)$ & $4(17)$ \\
\hline Not Included & $49(73)$ & $30(68)$ & $19(83)$ \\
\hline \multicolumn{4}{|l|}{ Therapeutic class } \\
\hline Cancer & $12(18)$ & $10(23)$ & $2(9)$ \\
\hline $\begin{array}{l}\text { Cardiovascular, diabetes, } \\
\text { or hyperlipidemia }\end{array}$ & $7(10)$ & $3(7)$ & $4(17)$ \\
\hline Gastrointestinal & $9(13)$ & $7(16)$ & $2(9)$ \\
\hline Infectious disease & $13(19)$ & $8(18)$ & $5(22)$ \\
\hline Neurology/psychiatry & $8(12)$ & $3(7)$ & $5(22)$ \\
\hline Other & $18(26)$ & $13(29)$ & $5(22)$ \\
\hline \multicolumn{4}{|l|}{ Approval year } \\
\hline 1939-1962 & $13(19)$ & $10(23)$ & $3(13)$ \\
\hline 1963-1984 & $20(30)$ & $15(34)$ & $5(22)$ \\
\hline 1985-present & $34(51)$ & $19(44)$ & $15(65)$ \\
\hline
\end{tabular}

${ }^{a}$ Orphan status designation began in 1983, so the number of orphan vs. non-orphan designated drugs differs from the total number of drugs FDA Food and Drug Administration, WHO World Health Organization differences were likely not statistically significant because of the relatively small number of drugs in monopolies or duopolies, which also limits the generalizability of our findings, as well as the inconsistent availability of pricing information.

Individual companies have drawn public ire for raising drug prices after acquisition, and in most cases, acquisitions do not lead to drug or delivery modifications, providing no additional value for patients or justification for price increases. Theoretically, the solution would be to cap price increases for offpatent drugs that have not undergone meaningful, clinically relevant improvements. In the meantime, the FDA's recent plan to accelerate generic drug approvals in markets with insufficient competition is encouraging, ${ }^{6}$ but along with other federal agencies, it should also consider the impact of market concentration when approving mergers or acquisitions.

\section{Acknowledgments:}

Data access and responsibility: Dr. Gupta and Ms. Henkel had full access to all the data in the study and take responsibility for the integrity of the data and the accuracy of the data analysis.

Funding/support and role of the sponsor: This project was not supported by any external grants or funds.

Corresponding Author: Joseph S. Ross, MD, MHS; Department of Health Policy and ManagementYale University School of Public Health, New Haven, CT, USA (e-mail: joseph.ross@yale.edu).

Author contributions All authors were responsible for the conception and design of this work. Dr. Gupta and Dr. Ross drafted the manuscript. Dr. Gupta conducted the statistical analysis. Dr. Gupta and Ms. Henkel were responsible for acquisition of data. Dr. Ross provided supervision. All authors participated in the interpretation of the data and critically revised the manuscript for important intellectual content. 


\section{Compliance with ethical standards:}

Conflict of interest: Dr. Gupta is supported by the Yale UniversityMayo Clinic Center of Excellence in Regulatory Science and Innovation (CERSI). The analysis presented in this paper was completed while Ms. Henkel was an undergraduate at Yale University and was included in her unpublished senior thesis in 2017. She has since graduated from Yale University and is now employed by Morgan Stanley. In the past 36 months, Dr. Ross has received research support through Yale University from Johnson and Johnson to develop methods of clinical tria data sharing, from Medtronic, Inc. and the Food and Drug Administration (FDA) to develop methods for postmarket surveillance of medical devices (UO1FD004585), from the Food and Drug Administration to establish Yale-Mayo Clinic Center for Excellence in Regulatory Science and Innovation (CERSI) program (U01FD005938), from the Blue Cross Blue Shield Association to better understand medical technology evaluation, from the Centers of Medicare and Medicaid Services (CMS) to develop and maintain performance measures that are used for public reporting, from the Agency for Healthcare Research and Quality to examine community predictors of healthcare quality (RO1HSO22882), and from the Laura and John Arnold Foundation to establish the Good Pharma Scorecard at Bioethics International and to establish the Collaboration for Research Integrity and Transparency (CRIT) at Yale. Dr. Forman has no conflicts of interest to disclose.

\section{REFERENCES}

1. U.S. Government Accountability Office. Part D generic drug prices declined overall but some had extraordinary price increases. Available at: http://www.gao.gov/assets/680/679022.pdf. Accessed 22 February 2018.

2. Dave CV, Kesselheim AS, Fox ER, Peihua Qiu P, Hartzema A. High Generic Drug Prices and Market Competition: A Retrospective Cohort Study. Annals of Internal Medicine. 2017;167(3):145-151.

3. Alpern JD, Stauffer WM, Kesselheim AS. High-cost generic drugs-implications for patients and policymakers. N Engl J Med. 2014;371(20): 1859-62.

4. Shakil S, Redberg RF. New (Very High) Prices on Old Drugs. JAMA Intern Med. 2017;177(11):1568.

5. Gupta R, Kesselheim AS, Downing N, Greene J, Ross JS. Generic Drug Approvals Since the 1984 Hatch-Waxman Act. JAMA Intern Med. 2016;176(9):1391-3.

6. U.S. Food and Drug Administration. Prioritization of the Review of Original ANDAs, Amendments, and Supplements. Available at: https:// www.fda.gov/downloads / AboutFDA/Centers Offices / OfficeofMedicalProductsandTobacco/CDER/ManualofPoliciesProcedures/ UCM407849.pdf. Accessed 22 February 2018 